\title{
Correction to: Classroom dialogue and digital technologies: a scoping review
}

\author{
L. Major ${ }^{1} \cdot$ P. Warwick ${ }^{1} \cdot$ I. Rasmussen ${ }^{2} \cdot$ S. Ludvigsen ${ }^{2} \cdot$ V. Cook ${ }^{1}$ \\ Published online: 27 March2019 \\ (C) Springer Science+Business Media, LLC, part of Springer Nature 2019
}

\section{Correction to: Educ Inf Technol (2018) 23:1995-2028 https://doi.org/10.1007/s10639-018-9701-y}

The authors of this review [1] wish to draw the attention of readers to a correction for Section 3.3.2. The text relating to [S11], a paper by Deaney, Chapman, \& Hennessy (2009) [2], is not an accurate representation of the work of the authors of this 2009 paper.

Section 3.3.2, paragraph 5, should be corrected to read:

"The multimodal nature of digital technologies, noted by 7 studies, allows for greater flexibility in the delivery of resources. For example, the IWB boasts visual, auditory, and text-based functions [S46], and the critical interplay of dialogue with visual and kinesthetic affordances of the IWB and other resources has been shown to support subject-based thinking [S11]. The use of digital technology can also have a positive impact on the pace of lessons [S19, S42, S45, S62, S72]. From a teacher's perspective, increased pace enables teachers to display information rapidly and spontaneously [S19, S42, S62]. From the students' perspective, students may feel that they have greater control over their learning as they may be able to dictate the speed at which they work [S72]."

The authors (Deaney, Chapman, \& Hennessy) were clearly referring to properties of a specific technology and not to learners. We would like to thank the authors of the 2009 paper for pointing out the need for this correction.

The online version of the original article can be found at https://doi.org/10.1007/s10639-018-9701-y

L. Major

lcm54@cam.ac.uk

1 Faculty of Education, University of Cambridge, 184 Hills Road, Cambridge CB2 8PQ, UK

2 Department of Education, University of Oslo, PO Box 1092, Blindern, Sem Sælands vei 7, 0317 Oslo, Norway 
[1] Major, L., Warwick, P., Rasmussen, I. et al. Educ Inf Technol (2018) 23: 1995. https://doi.org/10.1007/s10639-018-9701-y

[2] Deaney, R., Chapman, A., Hennessy, S., The Curriculum Journal (2009), Volume 20, Issue 4. https://doi.org/10.1080/09585170903424898

Publisher's note Springer Nature remains neutral with regard to jurisdictional claims in published maps and institutional affiliations. 